\title{
Patterns of energy intake in patients with cirrhosis and healthy volunteers
}

\author{
Angela M. Madden and Marsha Y. Morgan* \\ University Department of Medicine, The Royal Free Campus, The Royal Free and University College Medical School, \\ London NW3 2QG, UK
}

(Received 5 October 1998 - Revised 9 February 1999 - Accepted 8 March 1999)

\begin{abstract}
Fuel utilization and $\mathrm{N}$ economy are optimized in patients with cirrhosis by provision of several small meals throughout the day and a late-night snack of complex carbohydrate. Currently, however, only limited information is available on the patterns of energy intake in patients with chronic liver disease. The aims of the present study were to determine the number of days required to undertake such an investigation and to observe the daily distribution of energy intake in this patient population. Eight patients with cirrhosis and eight matched healthy volunteers kept weighed dietary intake records for fifteen separate days over a 6-month period. The records were analysed for energy intake per hour and the number and size of energy intake episodes per $24 \mathrm{~h}$ calculated. Intake was verified against resting energy expenditure. Fourteen separate observational days were required to investigate the pattern of energy intake in the cirrhotic patients while $20 \mathrm{~d}$ were required for healthy volunteers. Considerable inter- and intrasubject variations in the number and size of energy intake episodes were observed in both the patients and healthy volunteers. However, no significant differences were observed between the mean total number of daily energy intake episodes (6.3 (SD 1.6) v. 7.0 (SD 1.4)) or in the distribution of daily energy intake between the two groups. Most patients and volunteers tended to eat frequent small meals, often including a late-night snack, rather than two or three large meals daily. It should, therefore, be possible to establish optimum patterns of energy intake in these patients in line with recent guidelines.
\end{abstract}

Energy intake: Dietary patterns: Liver cirrhosis

Patients with cirrhosis have reduced hepatic glycogen stores (Nilsson, 1973). In consequence, hepatic gluconeogenesis and lipolysis are increased, at least in the fasting state, and this may have detrimental metabolic and nutritional effects (Owen et al. 1983). Provision of small frequent meals throughout the waking hours, together with a late-night snack, has been shown to improve fuel utilization and $\mathrm{N}$ economy in these individuals (Swart et al. 1989; Zillikens et al. 1993; Verboeket-van de Venne et al. 1995; Chang et al. 1997). In consequence, recommendations have been made that these patients should take four to seven small meals throughout their waking hours together with a latenight intake of complex carbohydrate (Plauth et al. 1997). However, before any attempt is made to manipulate intake in this patient population an appreciation of typical eating patterns is needed.

There is no published information on the length of time over which dietary intake would need to be assessed in patients with cirrhosis, or indeed healthy volunteers, in order to reliably estimate energy intake patterns (Bingham, 1987; Levine \& Morgan, 1991). In consequence, little if any information is available on meal patterning or on the frequency of energy intake in patients with cirrhosis (Verboeket-van de Venne et al. 1993).

Thus the aims of the present study were, in a group of patients with cirrhosis and a matched population of healthy volunteers, (1) to determine the number of days over which dietary intake should be assessed in order to reliably estimate patterns of energy intake; (2) to observe the daily distribution of energy intake from weighed intake records using measures of resting energy expenditure (REE) for verification.

\section{Subjects and methods}

The patient population comprised four men and four women with cirrhosis, recruited from outpatients attending the University Department of Medicine at the Royal Free Hospital. The median age at the beginning of the study was 54.5 (range 36-63) years (Table 1).

The aetiology of their liver disease was determined from historical, clinical, laboratory and histological variables. Seven of the patients had alcoholic cirrhosis; they had been abstinent from alcohol for a mean of 17.9 (range 4-36) 


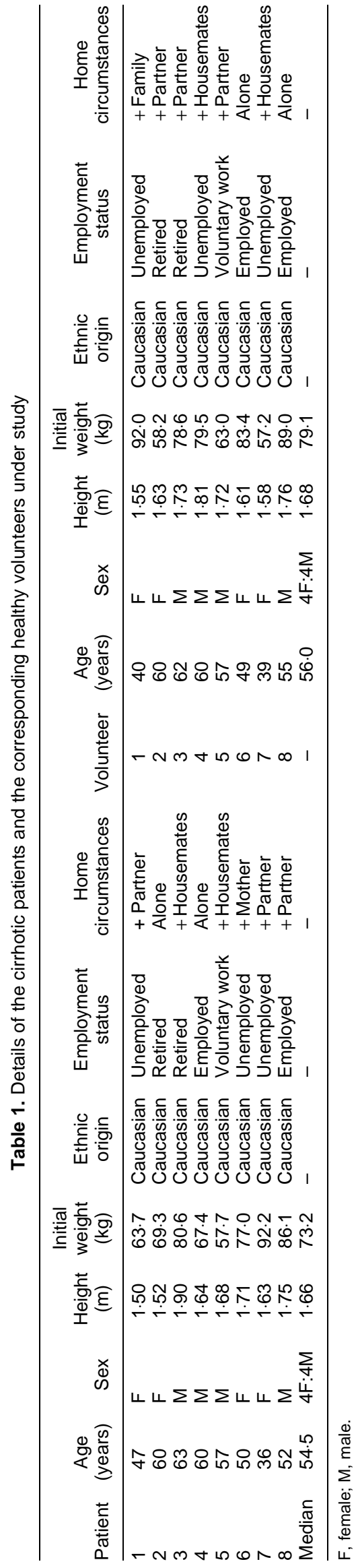

months before recruitment and remained abstinent for the duration of the study. The remaining patient had cirrhosis secondary to primary sclerosing cholangitis. The severity of liver injury was assessed using Pugh's modification of the Child's grading system (Pugh et al. 1973). Seven of the patients had stable, compensated disease with Pugh's scores of between 5 and 7. The remaining patient had stable but decompensated disease with a Pugh's score of 8. Five patients were on long-term medication for treatment of complications of their liver disease, including propanolol and isosorbide mononitrate (no. 6); diuretics (nos. 3 and 8) and non-absorbable disaccharides (nos. 2, 3 and 8). None of the patients was following a special diet or taking nutritional supplements, nor had the patients been advised to alter their food intake in any way.

Eight healthy individuals were selected from a pool of volunteer subjects who had taken part in previous research studies and who were known to be compliant and reliable. The volunteers were selected to pair-match the patients in terms of age, sex and ethnicity and general level of reported daily activity; they were also group-matched with the patients for height, weight, employment status, home, social and domestic circumstances. None of the healthy volunteers gave a history nor had clinical or laboratory evidence of either alcohol misuse or chronic liver disease; none was on long-term medication. Their median age at the beginning of the study was 56.0 (range 39-62) years (Table 1).

The study was undertaken over a 6-month period during which all subjects were living in their own homes. Five separate weeks were selected for the assessment of food intake during this time, thereby accounting for seasonal variations in eating habits. During each of the five selected weeks the subjects kept weighed records of their food intake for three $24 \mathrm{~h}$ periods of which two were weekdays and one a weekend day. Thus, in total, subjects provided fifteen separate $24 \mathrm{~h}$ food records during the 6-month study period.

All subjects were taught to weigh their food using a standardized technique with battery-operated scales, with a tare facility, capable of weighing in $1 \mathrm{~g}$ units from 1 to $1000 \mathrm{~g}$ and in $2 \mathrm{~g}$ units from 1000 to $2000 \mathrm{~g}$ (Soehle, Murrhardt, Germany). Guidelines for food description were provided and carefully explained; data collection forms, specifically designed for this study, were also provided and their use detailed. Although subjects were instructed to record the times at which all food and drink items were consumed they were not aware that there was a specific interest in their pattern of food intake.

Data collection forms were returned to the investigators for analysis in batches of three. Food packaging and labels were returned if they provided nutritional information. Incomplete or ambiguous information was clarified by discussion with the subjects in person or by telephone. Where food weights had been omitted an approximation was made based on the description of the food size in household measurements and published data (Crawley, 1988).

All food records were coded by one investigator (A. M. M.) for computation of energy content using Dietplan5 (Forestfield, Horsham, W. Sussex, UK).

REE was measured in all subjects, using an indirect, flowthrough, hood calorimeter (SensorMedics, Bilthoven, The 
Netherlands), in order to check the validity of the food records. The calorimeter was calibrated volumetrically and analytically at the beginning of each assessment using gas mixtures of fixed concentrations confirmed by chemical analyses.

Subjects attended for assessment between 08.00 and 11.00 hours having fasted for $6-8 \mathrm{~h}$. They were lightly clothed and had been instructed to evacuate their bladder and bowel beforehand. They lay supine on the calorimetry couch in thermal comfort at $22-26^{\circ}$. They were asked to relax, to stay awake but to remain still and avoid talking. After a rest period of $30 \mathrm{~min}$ the calorimeter hood was placed in position and secured. Air was drawn through the system at a variable but measured rate of between 18 and 50 litres/min, and a sample extracted from the exhaust stream each minute for the duration of the assessment. The air sample was passed through a sample-conditioning system to equalize sample gas and calibration gas with ambient conditions and was then analysed for $\mathrm{O}_{2}$, using a $\mathrm{Zr}$ analyser, and for $\mathrm{CO}_{2}$, using an i.r. absorption analyser. Measurements of the $\mathrm{O}_{2}$ and $\mathrm{CO}_{2}$ concentrations in the expired air and the gas flow rate were recorded every minute for the next $30 \mathrm{~min}$. A $24 \mathrm{~h}$ urine specimen was collected for measurement of urinary urea which was measured using a standard procedure (MacKay \& MacKay, 1927; Neumann $\&$ Ziegenhorn, 1977).

The reproducibility of the REE and RQ measurements was evaluated in three patients and three healthy volunteers over one $5 \mathrm{~d}$ period.

The data obtained on expired gas concentrations, gas flow rates and $24 \mathrm{~h}$ urinary $\mathrm{N}$ excretion were entered into a computer program and standard formulas applied (Bursztein et al. 1989) to calculate REE values for each 1 min period. Mean $24 \mathrm{~h}$ values were extrapolated from data collected from 5 to $30 \mathrm{~min}$. The ratio mean calculated total energy intake : measured REE, known as the physical activity level (PAL) was then calculated (Goldberg et al. 1991). Cut-off points for PAL values vary depending on the number of individuals studied and the length of time over which food records are collected. Comparisons of energy intake in the present study were made against a cut-off of $1 \cdot 17$, the published PAL value for plausible measures of actual diet of an individual subject during a measurement period of $14 \mathrm{~d}$ (CUT-OFF 2) with $95 \%$ confidence limits (Goldberg et al. 1991). Calculated PAL values below 1.17 are considered incompatible with long-term health and, unless the subject has lost weight, most likely indicate an under-reporting of food intake (Goldberg et al. 1991).

The patients were monitored throughout the study in the Out-patient Department. Physical status, body weight, reported levels of physical activity and laboratory test results were recorded every 4-6 weeks. The healthy volunteers were monitored by monthly telephone calls, occasional visits throughout the duration of the 6-month study period and a final visit on completion.

\section{Statistical analysis}

The food records were divided into $1 \mathrm{~h}$ periods and the energy intake calculated for each hour separately. Any $1 \mathrm{~h}$ period in which energy was consumed was described as an energy intake episode; the energy consumed during each of these episodes was expressed as a percentage of the total $24 \mathrm{~h}$ energy intake.

The CV for the total number of energy intake episodes per day was calculated for each subject from the fifteen separate $24 \mathrm{~h}$ food records and group mean values derived. The number of days of observation required to provide a reliable estimate of the total number of energy intake episodes per day was calculated using the method of Balogh et al. (1971):

$$
\text { number of days }=\frac{\text { coefficient of } \text { variation }^{2}}{\text { standard } \text { error }^{2}} .
$$

Comparisons were made between demographic, anthropometric and energy intake variables in the two subject groups using Wilcoxon signed-rank tests. The group mean numbers of energy intake episodes were calculated from individual mean values, and intergroup comparisons made using paired Student's $t$ test on the basis of the normalizing effects of the central limit theorem. Individual mean energy intakes were displayed as intake-time plots to facilitate visual examination of energy intake distribution throughout an average $24 \mathrm{~h}$ period for both the patients and healthy volunteers. Statistical analysis was undertaken using the Minitab software package (1991, State College, PA, USA).

\section{Results}

Subject stability

The patients showed a small but insignificant decrease in median BMI from 27.2 to $27.0 \mathrm{~kg} / \mathrm{m}^{2}$ over the 6-month study period with a range of weight change from -5.4 to $+5.2 \mathrm{~kg}$ (median $+0.5 \mathrm{~kg}$ ) (Fig. 1). The healthy volunteers showed a correspondingly small and insignificant decrease in median

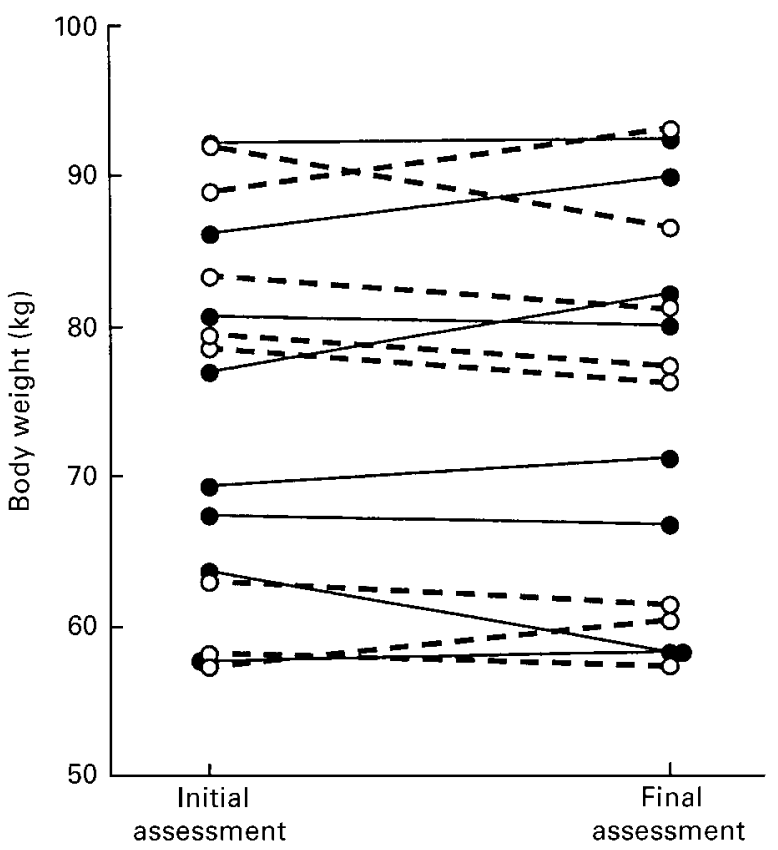

Fig. 1. Body weight in eight patients with cirrhosis $(\bullet-\bullet)$ and eight healthy volunteers $\left(\mathrm{O}_{-}-\mathrm{O}\right)$ at the beginning of the study and on its completion. 
Table 2. Median daily energy intake (EI) over a 6-month period, resting energy expenditure (REE), weight change and the physical activity level $(P A L)$ in eight patients with cirrhosis and eight healthy volunteers

\begin{tabular}{|c|c|c|c|c|c|c|c|c|c|}
\hline \multicolumn{5}{|c|}{ Patients with cirrhosis } & \multicolumn{5}{|c|}{ Healthy volunteers } \\
\hline 2 & 6530 & 6220 & +1.9 & 1.05 & 2 & 5670 & 5400 & -0.7 & 1.05 \\
\hline 3 & 10690 & 7860 & -0.5 & 1.36 & 3 & 9410 & 6500 & $-2 \cdot 2$ & 1.45 \\
\hline 4 & 7620 & 7200 & -0.6 & 1.06 & 4 & 11070 & 7830 & $-2 \cdot 1$ & 1.41 \\
\hline 7 & 4800 & 8620 & +0.4 & 0.56 & 7 & 8790 & 4140 & $+3 \cdot 3$ & $2 \cdot 12$ \\
\hline 8 & 12910 & 8150 & +3.9 & 1.58 & 8 & 11000 & 8350 & $+4 \cdot 2$ & 1.32 \\
\hline Median & 7675 & 7250 & +0.5 & $1 \cdot 13$ & Median & 9100 & 6905 & -1.7 & 1.37 \\
\hline
\end{tabular}

* Mean value from fifteen separate days.

† Single measure.

BMI from $25 \cdot 3$ to $24.9 \mathrm{~kg} / \mathrm{m}^{2}$ with a range of weight change from $-5 \cdot 3$ to $+4.2 \mathrm{~kg}$ (median $-1.7 \mathrm{~kg}$ ) (Fig. 1). No change was observed in the clinical status of the cirrhotic patients as evidenced by their Pugh's scores (Pugh et al. 1973).

\section{Energy intake}

There was no significant difference in median daily energy intake between the patients and healthy volunteers (7675 (range 4800-12910) v. 9100 (range 5670-11790) kJ/d); the CV for the two groups were 29 and $32 \%$ respectively. Similarly there was no significant difference in the median $\mathrm{CV}$ for intrasubject energy intakes between assessments in the patient and control populations (21 (range 9-30) $v$. 16 (range 9-28) \%).

\section{Energy expenditure}

The repeatability coefficients for measurement of REE and RQ were $2.1 \%$ and $1.3 \%$ in the patients with cirrhosis and $3.0 \%$ and $1.9 \%$ in the healthy volunteers respectively.

In six $(75 \%)$ of the patients and seven $(88 \%)$ of the healthy volunteers energy intake exceeded measured REE; the median group PAL values were 1.13 (range $0.56-1.58$ ) in the patients and 1.37 (range $0 \cdot 81-2 \cdot 12$ ) in the healthy volunteers (Table 2). PAL values exceeded 1.17 in four $(50 \%)$ patients and in five $(62 \%)$ healthy volunteers. In one patient (no. 7) with a low PAL value, 24h REE was considerably higher than in the paired healthy volunteer $(8620 v .4140 \mathrm{~kJ} / \mathrm{d})$; another one of these patients (no. 1) lost $5.4 \mathrm{~kg}$ in weight over the study period. The three volunteers with PAL values below $1 \cdot 17$ (nos. 1, 2 and 6) lost 5.3, 0.7 and $2.0 \mathrm{~kg}$ respectively during the course of the study.

\section{Validity of number of days studied}

Each subject provided fifteen separate $24 \mathrm{~h}$ weighed records as requested, and all were of sufficient quality for computation and analysis. The mean CV for the total number of daily energy intake episodes for the patients was $19 \%$ and for the volunteers was $22 \%$. Therefore, to predict the total number of daily energy intake episodes, with a $95 \%$ probability (Balogh et al. 1971), fourteen separate observational days are required for the patients with cirrhosis and $20 \mathrm{~d}$ for the healthy volunteers. Thus, in the present study, the patients' data are predictive with $95.0 \%$ confidence limits, the healthy volunteer data with $94.3 \%$ confidence limits.

\section{Patterns of nutrient intake}

There was considerable intersubject variation in nutrient intake patterns in both study groups; some subjects ate several small, snack-type meals whilst others consumed one large meal daily. The group $\mathrm{CV}$ for the total number of daily energy intake episodes was $25 \%$ for the patients and $20 \%$ for the healthy volunteers. There was, however, less intrasubject variation in nutrient intake in the patients with respective median individual CV of 18 (range 16-26) \% and 22 (range 11-28)\%; this difference was not significant.

There was no significant difference between patients and healthy volunteers in the mean total number of daily energy intake episodes (6.3 (SD 1.6) v. 7.0 (SD 1.4)). Similarly, no significant differences were observed between patients and healthy volunteers with respect to the number of energy intake episodes comprising less than $10 \%$ or more than 10 , $20,30,40$ or $50 \%$ of the total daily energy intake (Table 3; Fig. 2).

No overall differences were observed in either study group between the median daily energy intake in individuals consuming more or less frequently than average, as defined by the group median number of eating episodes (patients: 7890 (range 4800-12910) v. 7670 (range 6530-8830) kJ/d; healthy volunteers: 9410 (range 8790-11070) v. 6890 (range 5670-11780] kJ/d).

\section{Distribution of energy intake}

The patterns of energy intake in individual subjects varied (Fig. 3) but showed no obvious difference between the patients and healthy volunteers, although in both groups the greatest proportion of energy intake was consumed between 09.00 and 23.00 hours. 
Table 3. Intake episodes in eight patients with cirrhosis $(P)$ and eight healthy volunteers $(\mathrm{V})$ (Mean values for $15 \mathrm{~d}$ )

\begin{tabular}{|c|c|c|c|c|c|c|c|c|c|c|c|c|c|c|}
\hline \multirow{2}{*}{$\begin{array}{l}\text { Pair matched } \\
\text { patients and } \\
\text { volunteers }\end{array}$} & \multicolumn{2}{|c|}{$\begin{array}{l}\text { Total intake } \\
\text { episodes } \\
(n)\end{array}$} & & & \multicolumn{10}{|c|}{ Intake episodes by energy as a percentage of total daily energy intake $(n)$} \\
\hline & $P$ & $\mathrm{~V}$ & $P$ & $\mathrm{~V}$ & $P$ & $\mathrm{~V}$ & $P$ & $\mathrm{~V}$ & $P$ & $\mathrm{~V}$ & $P$ & $\mathrm{~V}$ & $\mathrm{P}$ & $\mathrm{V}$ \\
\hline 1 & $6 \cdot 2$ & 5.9 & 1.7 & 3.0 & 4.5 & 2.9 & 1.9 & $2 \cdot 1$ & 0.7 & 1.4 & 0.2 & 0.7 & 0.1 & 0.3 \\
\hline 2 & $5 \cdot 3$ & 5.6 & $2 \cdot 0$ & $2 \cdot 2$ & $3 \cdot 3$ & 3.4 & $2 \cdot 1$ & $2 \cdot 0$ & $1 \cdot 3$ & 1.5 & 0.8 & 0.5 & 0.3 & 0.1 \\
\hline 3 & 7.0 & 7.9 & 3.8 & $4 \cdot 1$ & 3.2 & 3.8 & $2 \cdot 1$ & $2 \cdot 3$ & $1 \cdot 1$ & 0.9 & 0.5 & 0.1 & 0.1 & 0 \\
\hline 7 & 7.4 & $9 \cdot 1$ & 4.8 & $5 \cdot 1$ & 2.6 & 4.0 & $2 \cdot 2$ & 1.6 & 1.3 & 0.8 & 0.9 & 0.3 & 0.6 & 0.1 \\
\hline 8 & $9 \cdot 3$ & 5.9 & $6 \cdot 1$ & $2 \cdot 6$ & 3.2 & $3 \cdot 3$ & $1 \cdot 6$ & $2 \cdot 1$ & $1 \cdot 3$ & 1.1 & 0.6 & 0.6 & 0.3 & 0.4 \\
\hline Mean & $6 \cdot 3$ & $7 \cdot 0$ & 2.9 & 3.5 & 3.3 & 3.5 & $2 \cdot 2$ & 2.0 & $1 \cdot 1$ & 1.1 & 0.6 & 0.4 & 0.3 & 0.2 \\
\hline SD & 1.6 & 1.4 & 1.9 & 1.2 & 0.8 & 0.4 & 0.4 & 0.2 & 0.3 & 0.3 & 0.3 & 0.2 & 0.3 & 0.2 \\
\hline
\end{tabular}

\section{Discussion}

The European Society for Parenteral and Enteral Nutrition (ESPEN) Consensus Group has recently recommended that fasting times in patients with cirrhosis should be no greater than $6 \mathrm{~h}$ (Plauth et al. 1997). This recommendation was based on evidence that (1) patients with cirrhosis have low hepatic glycogen stores (Nilsson, 1973) and show increased gluconeogenesis and lipolysis, at least in the fasting state (Owen et al. 1983); and (2) that these metabolic abnormalities can be corrected, at least in part, and the long-term effects on $\mathrm{N}$ balance thereby avoided, by provision of frequent small meals and a late-night snack of complex carbohydrate (Swart et al. 1989; Zillikens et al. 1993; Verboeket-van de Venne et al. 1995; Chang et al. 1997). However, it is generally accepted that it is difficult to change established food habits (Brownell \& Cohen, 1995) and thus, before attempting to impose these dietary recommendations it is necessary to determine existing feeding behaviour patterns in this patient population.

In Western countries, individuals tend to eat or take nourishment between five and seven times daily with a range of two to nine (British Nutrition Foundation, 1984; Schlettwein-Gsell, 1992; Summerbell et al. 1995; Gatenby, 1997). The terms 'meal' and 'snack' have been variously defined according to the time of consumption (Summerbell et al. 1995) and/or nutrient composition (Bernstein et al. 1981); these terms have limited value, however, in the context of defining overall patterns of nutrient intake. The concept of an energy intake episode, based on the percentage of total energy consumed within a $1 \mathrm{~h}$ period has not been used previously. This technique was designed to facilitate comparisons of relative patterns of energy intake without the need to define either a minimum amount of energy consumed or a time period between discreet episodes (de Castro, 1993). In addition, in the clinical situation, where nutrient intake is not limited to the food eaten but might include supplementary drinks or enteral tube feeding, a broader notion of 'intake' is required than one defined by eating alone.

In the present study, the collection of dietary intake data over fifteen observational days yielded results predictive of the total number of daily energy intake episodes with $95.0 \%$ and $94.3 \%$ confidence limits in the patients and healthy

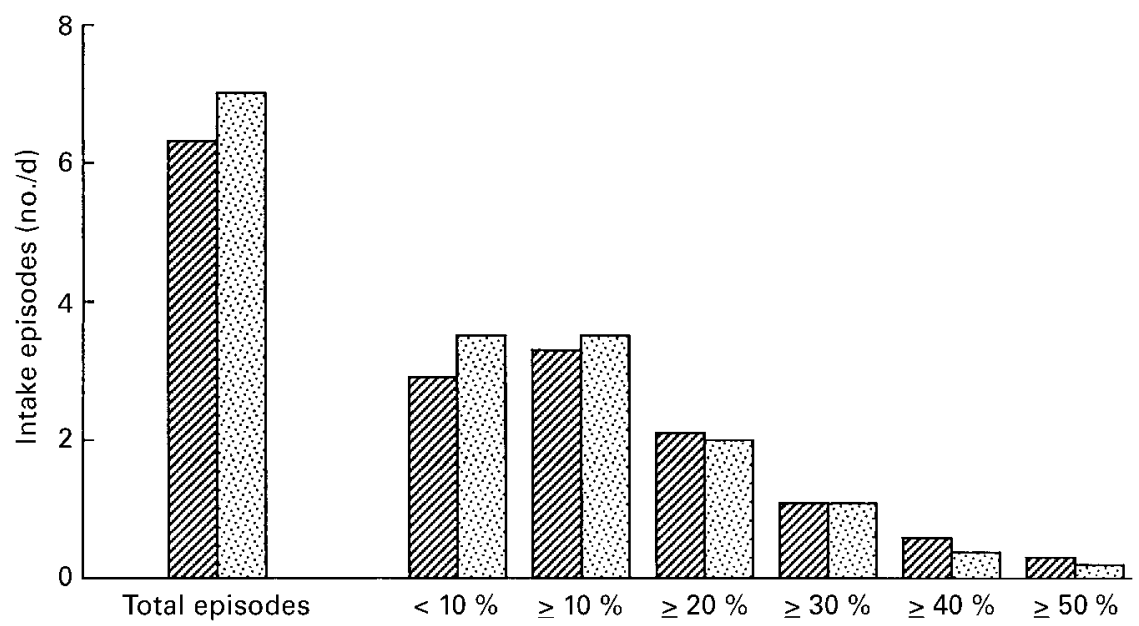

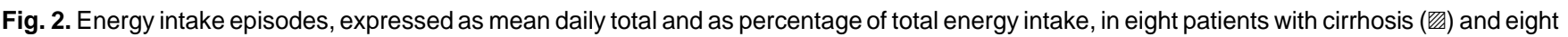
healthy volunteers (圆). Values are means of eight subjects' mean values for $15 \mathrm{~d}$. 
(a)
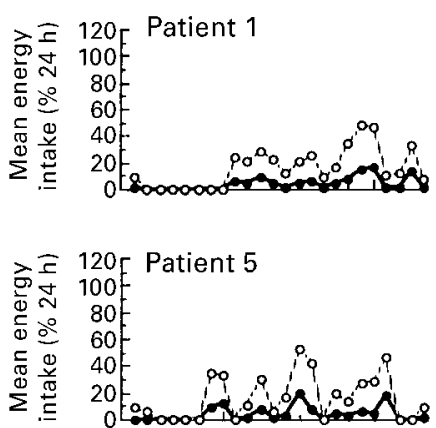

(b)
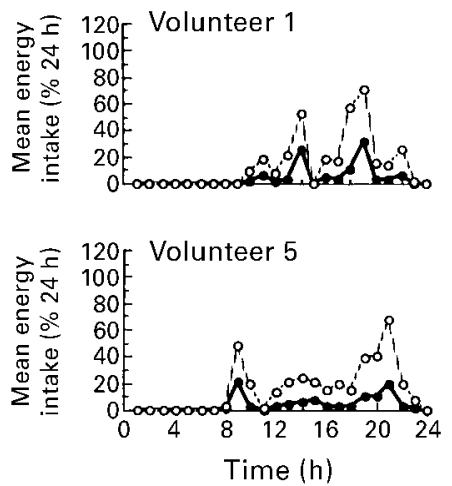
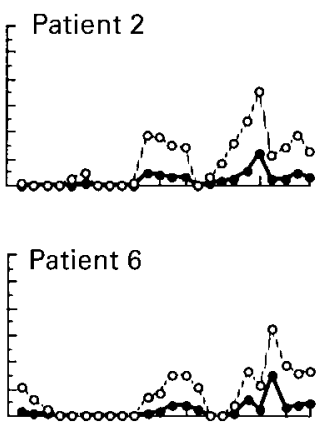
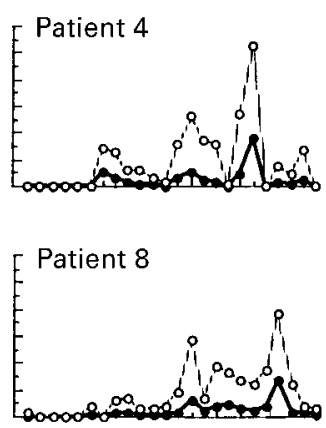
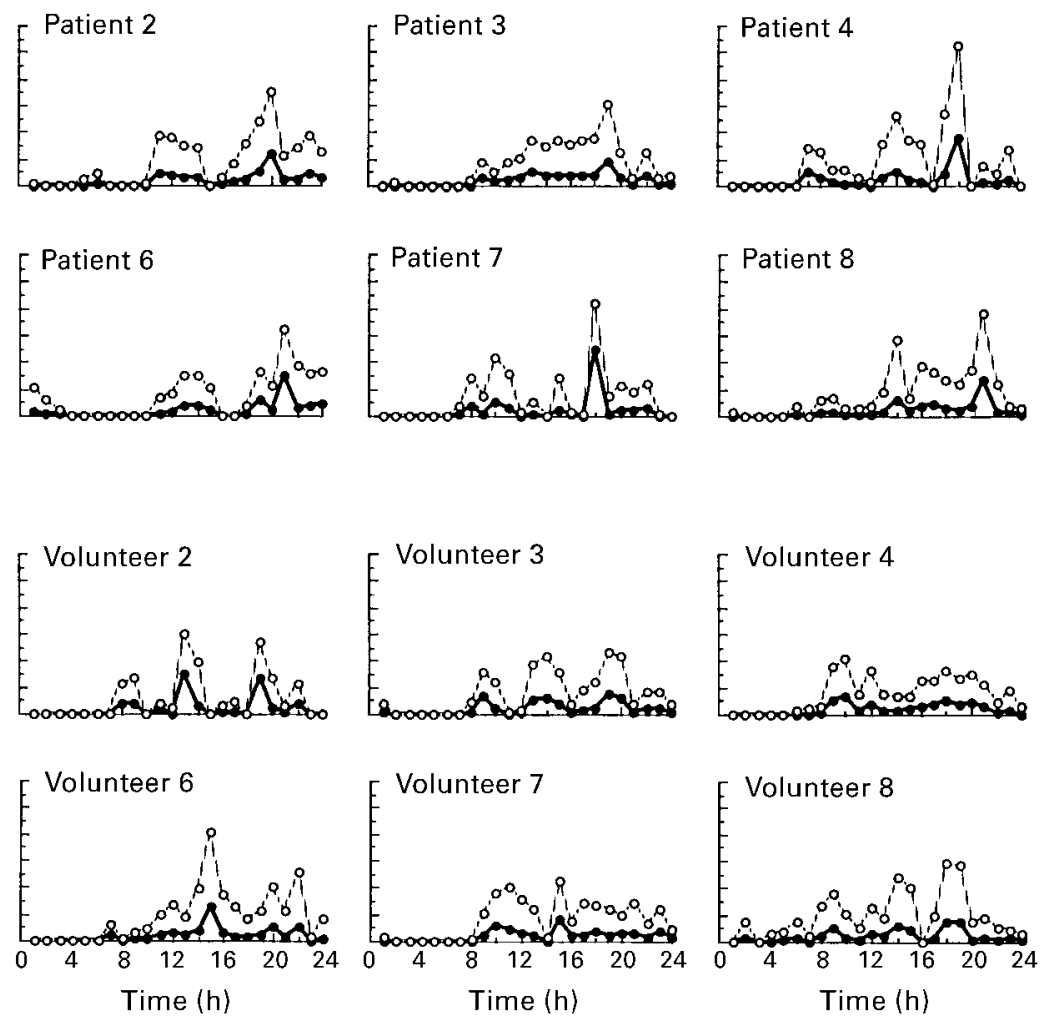

Fig. 3. Intake-time plots showing mean energy intake $(\bullet-\bullet)+2 S D\left(0_{--}\right)$per energy intake episode by hour throughout a $24 \mathrm{~h}$ period in $(\mathrm{a})$ eight patients with cirrhosis and (b) eight healthy volunteers.

volunteers respectively. Because of the larger $\mathrm{CV}$ in the total number of episodes in the healthy volunteers, observations would be required on $20 \mathrm{~d}$ to achieve predictions with 95.0\% confidence. However, for the purposes of the present study, the number of days observed was considered adequate.

Several investigative techniques have been used to examine the frequency of nutrient intake, including $24 \mathrm{~h}$ dietary recall (British Nutrition Foundation, 1984), questionnaires (Bellisle et al. 1997), $7 \mathrm{~d}$ weighed food records (Summerbell et al. 1996) or combinations of these (Kant, 1995). There is potential, with all techniques which rely on self assessment, for individuals to under-report their dietary intake (Bingham, 1987); this may be a particular problem with smaller 'snack' items of food. Thus, it has been recommended that energy intake data are validated by comparison with measures of REE and calculation of PAL (Gatenby, 1997).

In healthy individuals, a minimum value for the ratio between energy intake estimated from food intake records kept over $15 \mathrm{~d}$ and REE measured using indirect calorimetry, or PAL, of 1.17 is required for the long-term maintenance of energy balance (Goldberg et al. 1991). PAL values below 1.17 are considered incompatible with longterm health if the subject is in a stable clinical condition and, as such, suggest that they may be under-reporting their food intake. Values greater than 1.17 are not a guarantee of the validity of energy intake data but indicate that underreporting is less likely. This value has been derived from studies of healthy populations (Goldberg et al. 1991) and therefore extrapolation to individual patients with cirrhosis has limitations. It could be argued that the selection of a cut-off of $1 \cdot 17$, while appropriate for studies of approximately $15 \mathrm{~d}$, is too stringent given that the food records were kept over a selection of $3 \mathrm{~d}$ during five separate weeks. However, the use of a PAL cut-off limit of $1 \cdot 10$, for studies of approximately $3 \mathrm{~d}$, would not change the number of either patients or healthy volunteers failing to reach the cut-off.

In the present study four patients and three healthy volunteers had PAL values of less than 1.17 suggesting an imbalance of energy intake against expenditure or else under-reporting or modification of food intake on the days selected for record keeping. In one of the four patients the low PAL value undoubtedly reflected a hypermetabolic state; in one other patient the low PAL value could be explained by a reduction in energy intake over the study period manifest as significant weight loss. The remaining three patients with low PAL values most probably underreported their food intake, or modified their dietary intake on the days selected for recording. The latter is considered more likely in view of the method of open selection of the $3 \mathrm{~d}$ on which food records were kept each week (Larkin et al. 1991). However, the records were deemed, after careful scrutiny, to be consistently maintained and, therefore, acceptable for purposes of examining intake patterns. In all three of the healthy volunteers the low PAL values may be explained, at least in part, by reduction in energy intake manifest as weight loss during the course of the study.

The results from the present study differ from those reported by Verboeket-van de Venne et al. (1993) in which patients appeared to consume a significantly greater proportion of their energy intake in the first $4 \mathrm{~h}$ after rising 
than healthy volunteers. However, these differences can probably be explained by a number of methodological differences between the two studies. In the Verboeket-van de Venne et al. (1993) study, food intake was reported in one of seven designated food-periods and then expressed relative to the time of rising rather than absolute time. Circadian rhythms are disrupted in patients with cirrhosis with more nocturnal awakening and more frequent daytime naps than in healthy volunteers (Steindl et al. 1995) and this altered sleep pattern is likely to influence the time of rising, and thus the apparent timing of food intake. The patients in the two studies differed with regard to aetiology and severity of liver disease, medication, alcohol intake, hospitalization and previous dietary advice and this may have influenced their food intake. In addition, differences in the quality of the control populations used in the two studies will undoubtedly have influenced the results. In view of these differences, it is difficult to draw conclusions from the study of Verboeket-van de Venne et al. (1993).

The numbers of total daily energy intake episodes observed in the present study were comparable between the patients and healthy volunteers and concurred with most other published data (British Nutrition Foundation, 1984; Schlettwein-Gsell, 1992; Summerbell et al. 1995; Gatenby, 1997). In the present study, the number of energy intake episodes comprising less than $10 \%$, or more than $10,20,30$, 40 or $50 \%$ of the total daily energy intake, similarly, did not differ significantly between the two groups. Episodes comprising less than $10 \%$ of the total energy intake were not further subdivided as errors of the method exceeded the variations under observations (Bingham, 1987).

Most individuals had reasonably defined eating routines even though their food intake appeared to vary greatly in terms of the frequency and size of energy intake episodes. The intake-time plots do not lend themselves to statistical analysis, but clearly illustrate the variation in energy intake over an average $24 \mathrm{~h}$ period within and between individuals in both groups.

None of the patients taking part in the present study had been given specific advice to increase their frequency of food intake or to consume late-night snacks but the results from the present study suggest that most individuals are already doing so. Therefore, this pattern of intake should be easy to endorse in this patient population.

\section{Acknowledgements}

The authors wish to thank Dr Richard Morris, Department of Primary Care and Population Sciences, Royal Free Campus, The Royal Free and University College Medical Schools, for statistical advice, and all the patients and volunteers who took part so willingly in this study. Nestlé Clinical Nutrition (formerly Clintec Technologies), Velizy Cedex, France, purchased the computer dietary analysis program.

\section{References}

Balogh M, Kahn HA \& Medalie JH (1971) Random repeat 24-hour dietary recalls. American Journal of Clinical Nutrition 24, 3104-3110.
Bellisle F, McDevitt R \& Prentice AM (1997) Meal frequency and energy balance. British Journal of Nutrition 77, S57-S70.

Bernstein IL, Zimmerman JC, Czeisler CA \& Weitzman ED (1981) Meal patterning in 'free running'" humans. Physiology and Behavior 27, 621-623.

Bingham SA (1987) The dietary assessment of individuals; methods, accuracy, new techniques and recommendations. Nutrition Abstracts and Reviews 57, 705-742.

British Nutrition Foundation (1984) Eating in the Early 1980's. Attitudes and Behaviour: Main Findings. London: British Nutrition Foundation.

Brownell KD \& Cohen LR (1995) Adherence to dietary regimens. 2: Components of effective interventions. Behavioral Medicine 20, $155-164$.

Bursztein S, Elwyn DH, Askanazi J \& Kinney JM (1989) Energy Metabolism, Indirect Calorimetry, and Nutrition. Baltimore, MD: Williams \& Wilkins.

Chang WK, Chao YC, Tang HS, Lang HF \& Hsu CT (1997) Effects of extra-carbohydrate supplementation in the late evening on energy expenditure and substrate oxidation in patients with liver cirrhosis. Journal of Parenteral and Enteral Nutrition 21, 96-99.

Crawley H (1988) Food Portion Sizes. London: H.M. Stationery Office.

de Castro JM (1993) The effects of the spontaneous ingestion of particular foods or beverages on the meal pattern and overall nutrient intake of humans. Physiology and Behavior 53, 11331144.

Gatenby SJ (1997) Eating frequency: methodology and dietary aspects. British Journal of Nutrition 77, S7-S20.

Goldberg GR, Black AE, Jebb SA, Cole TJ, Murgatroyd PR, Coward WA \& Prentice AM (1991) Critical evaluation of energy intake data using fundamental principles of energy physiology: 1. Derivation of cut off limits to identify under-recording. European Journal of Clinical Nutrition 45, $569-581$.

Kant AK (1995) Frequency of eating occasions and weight changes in NHANES I Epidemiologic Follow-up Study. International Journal of Obesity and Related Metabolic Disorders 19, 468474.

Larkin FA, Metzner HL \& Guire KE (1991) Comparison of three consecutive-day and three random-day records of dietary intake. Journal of the American Dietetic Association 91, 15381542.

Levine JA \& Morgan MY (1991) Assessment of dietary intake in man: a review of available methods. Journal of Nutritional Medicine 2, 65-81.

MacKay EM \& MacKay LL (1927) Concentration of urea in blood of normal individuals. Journal of Clinical Investigation 2, 295.

Neumann U \& Ziegenhorn J (1977) Kinetic enzymatic method for the determination of urea in serum with the LKB 8600 reaction rate analyzer. Scandinavian Journal of Clinical and Laboratory Investigation 37, Suppl. 147, 90 Abstr. 97.

Nilsson LH (1973) Liver glycogen content in man in the postabsorptive state. Scandinavian Journal of Clinical and Laboratory Investigation 32, 317-323.

Owen OE, Trapp VE, Reichard GA, Mozzoli MA, Moctezuma J, Paul P, Skutches CL \& Boden G (1983) Nature and quantity of fuels consumed in patients with alcoholic cirrhosis. Journal of Clinical Investigation 72, 1821-1832.

Plauth M, Merli M, Kondrup J, Weimann A, Ferenci P \& Müller MJ (1997) ESPEN guidelines for nutrition in liver disease and transplantation. Clinical Nutrition 16, 43-55.

Pugh RNH, Murray-Lyon IM, Dawson JL, Pietroni MC \& Williams $\mathrm{R}$ (1973) Transection of the oesophagus for bleeding oesophageal varices. British Journal of Surgery 60, 646-649. 
Schlettwein-Gsell D (1992) Nutrition and the quality of life, a measure for the outcome of nutritional investigation. American Journal of Clinical Nutrition 55, 1263S-1266S.

Steindl PE, Finn B, Bendok B, Rothke S, Zee PC \& Blei AT (1995) Disruption of the diurnal rhythm of plasma melatonin in cirrhosis. Annals of Internal Medicine 123, 274-277.

Summerbell CD, Moody RC, Shanks J, Stock MJ \& Geissler C (1995) Sources of energy from meals vs snacks in 220 people in four age groups. European Journal of Clinical Nutrition 49, 33-41.

Summerbell CD, Moody RC, Shanks J, Stock MJ \& Geissler C (1996) Relationship between feeding pattern and body mass index in 220 free-living people in four age groups. European Journal of Clinical Nutrition 50, 513-519.

Swart GR, Zillikens MC, van Vuure JK \& van den Berg JWO
(1989) Effect of a late evening meal on nitrogen balance in patients with cirrhosis of the liver. British Medical Journal 299. $1202-1203$.

Verboeket-van de Venne WPHG, Westerterp KR, van Hoek B \& Swart GR (1993) Habitual pattern of food intake in patients with liver disease. Clinical Nutrition 12, 293-297.

Verboeket-van de Venne WPHG, Westerterp KR, van Hoek B \& Swart GR (1995) Energy expenditure and substrate metabolism in patients with cirrhosis of the liver: effects of the pattern of food intake. Gut 36, 110-116.

Zillikens MC, van den Berg JWO, Wattimena JLD, Rietveld T \& Swart GR (1993) Nocturnal oral glucose supplementation. The effects on protein metabolism in cirrhotic patients and in healthy controls. Journal of Hepatology 17, 377-383. 